\title{
Experimental Stress Analysis for Woven Carbon, Glass, and Kevlar Laminate Shells
}

\author{
Azad M. A. Saber, Khatoon Y. Ibrahim \\ Department of Mechanical Engineering, College of Engineering, University of Salahaddin, Erbil \\ azadsever@yahoo.com, khatoonyaseen@yahoo.com
}

\begin{abstract}
Composite shell structures have many applications in aerospace industry in which deal with various loading abundantly. In present paper Strain gauge instrument with rectangular rosette strain gauges were used to detect the maximum stress and strain distributions along the shell composite structure. Also a finite element analysis was done for validation of experimental results. The FEM software used was ANSYS14. Impact test, density measurement, and bending test were performed in order to detect physical and mechanical properties such as toughness, principal stresses, and density, of the three laminated composite shells. In addition, the results between experimental and ANSYS were compared. It was observed that an important discrepancy is found between theoretical and experimental results. It was also found a large difference in modulus of elasticity, toughness, and tensile strength for each composite material. These differences are tabulated in many tables in the last paper.
\end{abstract}

Keywords: Composite, Shell, Carbon fiber, Kevlar fiber, Glass fiber, ANSYS.

Paper History: (Received: 27/3/2017; Accepted: 18/7/2017)

\section{Introduction}

Composite materials are desirable in lightweight structures due to their high specific stiffness and strength. Woven carbon, glass, and Kevlar materials have great importance in aerospace and aircraft industries. The main reason leads to success of the use of composite materials. In the aerospace industry is high performance versus weight ratios that it is possible to achieve using these materials and on the necessity to lower the weight of the aircraft as much as possible to enhance its efficiency.

Shells are common structural elements in many engineering structures, including pressure vessels, submarine hulls, ship hulls, wings and fuselages of airplanes, pipes, and exteriors of rockets, missiles, automobile tires, concrete roofs, containers of liquids, and many other structures [1]. A shell is a curved, thin walled structure. A primary difference between a shell structure and a plate structure is that, in the unstressed state, the shell structure has curvature as opposed to plates. Shells have all the characteristics of plates, along with an additional one -curvature. There are two different classes of shells: thick shells and thin shells. The main advantage of shell structures are their ability to carry relatively large loads compared to their weight if designed correctly. Recently, a sustained attempt has been made in finding the static behavior of laminated composite shells having high strength-toweight ratio [2]. A stress analysis of stiffened cylindrical composite shell under transverse end load has been analyzed [3]. A new method for an elastic-plastic analysis of stress and deformation fields in composite overwrapped cylinder under the pressure load has been provided [4]. Experimental and numerical analysis of grid composite cylindrical shell subjected to transverse loading [5] and various end loading [6] have been made. Two layers composite tube are examined cyclically loaded in the elastic and elastic-plastic states [7]. Buckling analysis of thin walled composite cylindrical shells with and without cutouts under applying axial load on glass fiber reinforced plastic shell has been made [8].

The present paper provides a coupling between an experimental measuring using strain gauge technique and finite element method using ANSYS 14.

\section{Numerical Analysis}

ANSYS Release 14 was used to carry out the finite element analysis in the present work. ANSYS is used to analyze the principal stress distribution (the maximum principal stress distribution and the minimum principal stress distribution), also the Von Mises stress of the three laminated composite shells. The problem is solved using 2-D PLANE182 [9]. PLANE182 can be used as a plane element (plane stress and plane strain). The material properties are taken as constant and isotropic material because the fibers used are woven laminate. After modeling of the specimen and applying boundary conditions (fixed -fixed ends) and loads (point load in-Y direction at middle), the analysis carried out and obtain the 
results. Figure 1 shows the maximum and minimum principle stress distribution of the three laminated composite shells at different loads.
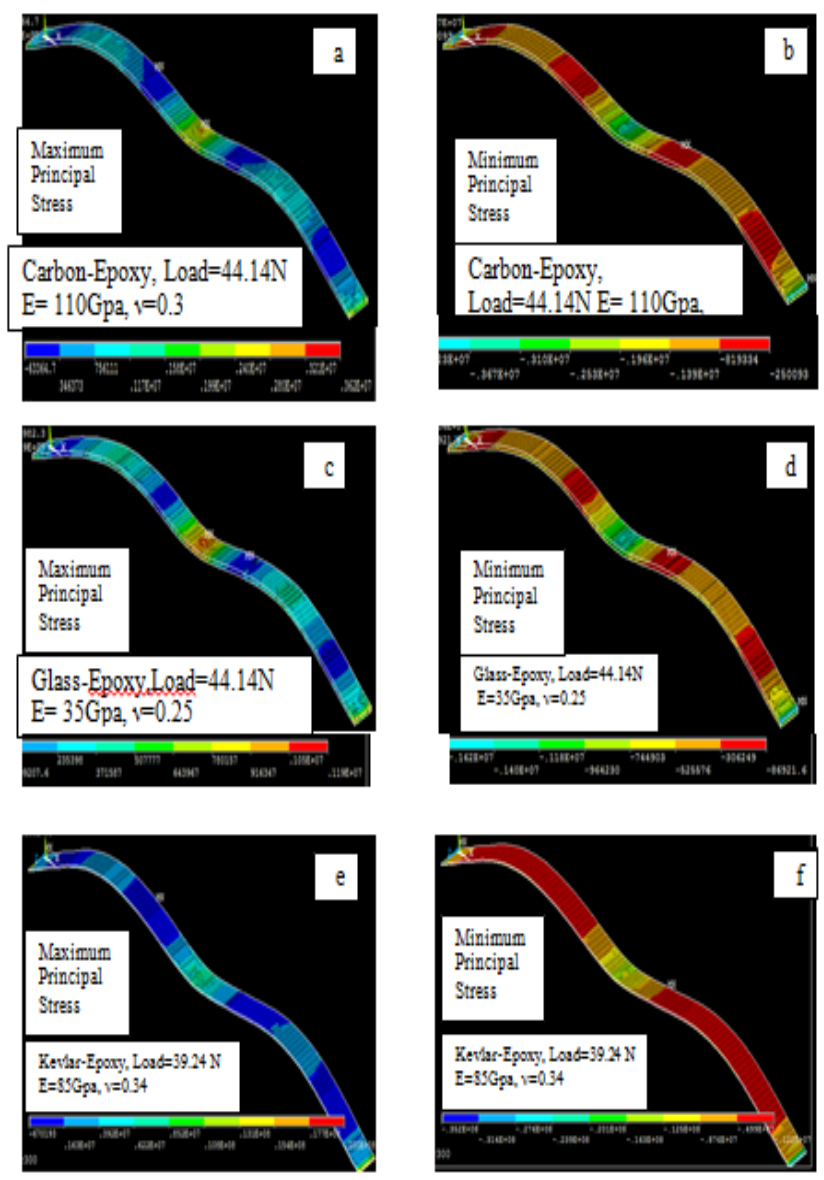

Figure 1: Maximum and Minimum principal stress distribution of three composite shells at different loads

\section{Experimental Work}

\subsection{Tensile Test}

The geometry of the specimen and instrument type is shown in Figure 2. Generally, rectangular specimens are required for the composite material characterization, because the "dog -bone" type tends to split in the region where the width changes. Still the grips of tension test frame introduce large stress concentration in the specimen. To minimize this effect tabs must be bonded on each side of the specimen. Tensile tests were carried out in accordance with ASTM standards D3039 [10], using a minimum of five specimens for each laminated composite. The results are shown in Table 1. The tensile experiments were carried out in Mechanical Engineering Department / Salahaddin University / Erbil. These tests are examined in order to get the necessary properties of three type's composite material (such as tensile stress and modulus of elasticity).
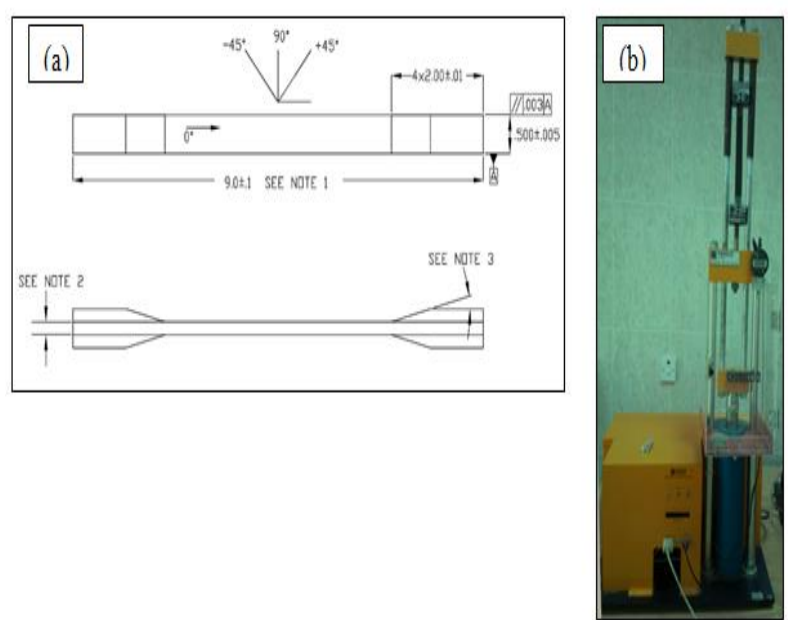

Figure 2: (a) Geometry of the specimen (b) MT 3037 Universal Testing (Specimen thickness between

(0.090-0.12) Tab bevel angle between $\left(5-90^{\circ}\right)$ All dimensions in inches

Table 1 Tensile Test results of the three composite materials.

\begin{tabular}{|c|c|c|}
\hline Material & $\begin{array}{c}\text { Modulus of Elasticity } \\
\text { (Gpa) }\end{array}$ & $\begin{array}{c}\text { Max. Tensile strength } \\
\text { (Mpa) }\end{array}$ \\
\hline Carbon-Epoxy & 110 & 500 \\
\hline Glass-Epoxy & 35 & 87 \\
\hline Kevlar-Epoxy & 85 & 370 \\
\hline
\end{tabular}

\subsection{Impact Test}

The specimen for Charpy impact test is rectangular with a notch cut in one side which is prepared according to ASTM standard D 6110 [11]. The Charpy impact test method works by placing the notched specimen (with the notch facing away from the point contact) horizontally on two supports into an instrument with a pendulum of a known weight. The pendulum is raised to known height and allowed to fall. As the pendulum swings, it impacts and breaks the specimen. The results are shown in Table 2. The instrument and the geometry of the specimen are shown in Figure 3. Impact experiments were carried out in Mechanical Engineering Department / Salahaddin University / Erbil. These tests are carried out in order to get the toughness values of three type's composite materials. 
Table 2 Comparison of impact energy of the three composite materials.

\begin{tabular}{|r|c|}
\hline Material & Absorbed Energy (J) \\
\hline Carbon-Epoxy & 2.1 \\
\hline Glass-Epoxy & 4.2 \\
\hline Kevlar-Epoxy & 6.3 \\
\hline
\end{tabular}
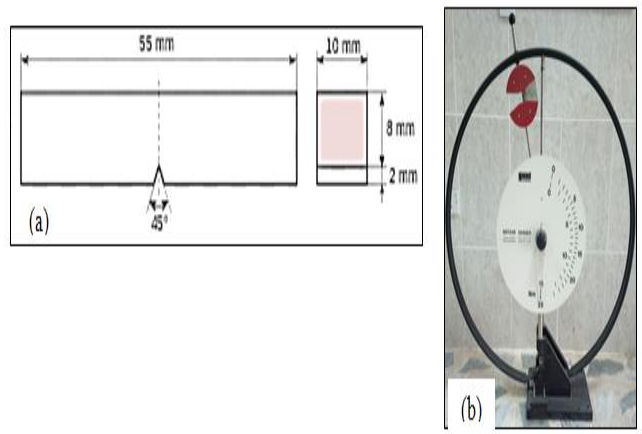

Figure 3: (a) Geometry of the Impact specimen (b) WP 400 Pendulum Impact Tester, 25Nm

\subsection{Density Measurement}

The density measurements of the composite material specimens were carried out according to ASTM D 792 [12]. The specimens can be prepared in any convenient size (the size $25 \mathrm{~mm} \times 25 \mathrm{~mm} \times$ thickness is normally used). Density was calculated by weighing the specimen in air and then the specimen weighted when immersed in distilled water at $23^{\circ} \mathrm{C}$ using a sinker and wire to hold the specimen completely submerged as required. Density measurement was carried out in Mechanical Engineering Department / Salahaddin University / Erbil. Density and Specific Gravity are calculated as follows:

Specific gravity $23 / 23^{\circ} \mathrm{C}=\mathrm{a} /[(\mathrm{a}+\mathrm{w})-\mathrm{b}]$

$\mathrm{a}=$ mass of specimen in air $(\mathrm{kg})$.

$\mathrm{b}=$ mass of specimen and sinker (if used) in water $(\mathrm{kg})$.

$\mathrm{W}=$ mass of totally immersed sinker if used and partially immersed wire $(\mathrm{kg})$.

Density $23^{\circ} \mathrm{C}, \mathrm{kg} / \mathrm{m}^{3}=$ Specific gravity $23 /$ $23^{\circ} \mathrm{C} \times(997.5)$

\subsection{Bending Test}

Bending tests were carried out in Mechanical Engineering Department / Salahaddin University / Erbil. In the bending test of the laminated composite shell structures the static load (different values) was applied at the middle of the structure as shown in Figure 4, and a dial gage to measure the deflection at the mid span was installed. First, to prevent prefailure at the ends, both ends of the specimen were put into the fixture to limit the specimen movement along horizontal and vertical directions. Due to symmetry, at the top face of the specimen the three rectangular strain gage rosettes were mounted at angle of $45^{\circ}$ at three positions ( $x=20 \mathrm{~mm}, \mathrm{x}=265 \mathrm{~mm}, \mathrm{x}=530 \mathrm{~mm}$ ) in order to measure strain states in three directions $\left(0^{\circ}, 45^{\circ}, 90^{\circ}\right)$ at specified points on the structure. In each steps the value of applied load, deflection and strains in three directions recorded. The three element strain gage rosette allows computing principal strains and principal stresses directly from measured strain gage data. The Equations 1, 2 and 3 were used to calculate the principal strains, the shear strain in xy-direction and the principal angle by substituting the measured experimental strains (instrument's reading) ${ }^{(13)} \varepsilon_{a}, \varepsilon_{b}, \varepsilon_{c}$

$$
\begin{gathered}
\varepsilon_{1,2}= \\
\frac{1}{\sqrt{2}} \sqrt{\left(\varepsilon_{\mathrm{a}}-\varepsilon_{\mathrm{b}}\right)^{2}+\left(\varepsilon_{\mathrm{b}}-\varepsilon_{\mathrm{c}}\right)^{2}} \\
\gamma_{x y}=2 \varepsilon_{b}-\left(\varepsilon_{a}+\varepsilon_{c}\right)(2) \\
\theta=\frac{1}{2} \tan ^{-1}\left(\frac{\varepsilon_{a}-2 \varepsilon_{b}+\varepsilon_{c}}{\varepsilon_{a}-\varepsilon_{c}}\right)
\end{gathered}
$$

Equation 4 express the principal stresses in terms the three measured experimental strains and the material properties.

$$
\begin{array}{cl}
\sigma_{1,2}=\frac{E}{2}[ & \frac{\varepsilon_{a}+\varepsilon_{c}}{1-v} \mp \\
\left.\frac{\sqrt{2}}{1+v} \sqrt{\left(\varepsilon_{a}-\varepsilon_{b}\right)^{2}+\left(\varepsilon_{b}-\varepsilon_{c}\right)^{2}}\right]
\end{array}
$$

The plus and minus alternatives in Equation 1 and 4 yield the algebraically maximum and minimum principal strains and principal stresses respectively. The equation (5) used to calculate the maximum shear stress in terms of three measured strains

$$
\tau_{\max }=\frac{E}{\sqrt{2}(1+v)} \sqrt{\left(\varepsilon_{a}-\varepsilon_{b}\right)^{2}+\left(\varepsilon_{b}-\varepsilon_{c}\right)^{2}}
$$

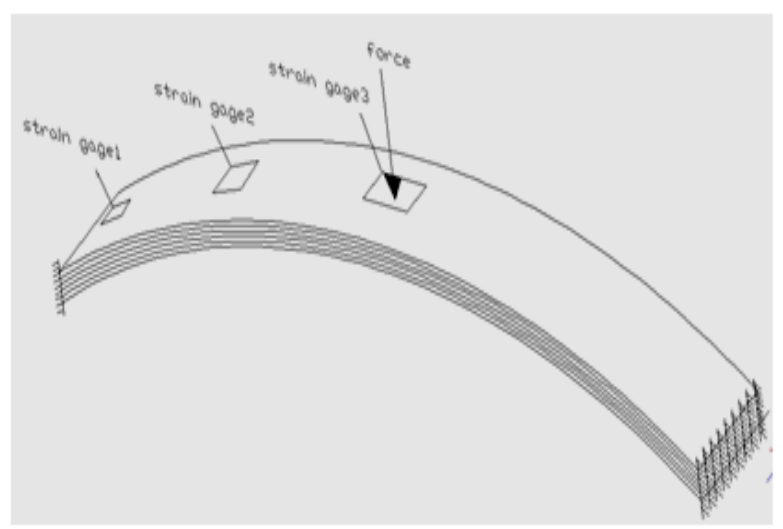

Figure 4: Geometry of the Bending specimen 


\subsection{Strain Gauge test}

Strain gauge test was carried out in Mechanical Engineering Department / Salahaddin University / Erbil. A strain gauge indicator P3500 was used to measure the strain through the shell composite. The device is used for three bridges: Quarter bridge, half bridge and full bridge. The maximum number of strain gauges that can be used in this instrument is ten strain gauges. Two types of strain gauges were used in this work, Single element strain gauge and rectangular Rosette strain gauge as shown in Figure 5. A single strain gauge was used to detect the Poisson's ratio $v$ for three types of composite. The rectangular Rosette strain gauge was used to measure the experimental principal strains and stresses and consequently the Von Mises stress in bending test for three types of composite shell, Carbon, Glass, and Kevlar as a reinforced fibers with epoxy material as a matrix material as shown in Figure 6.

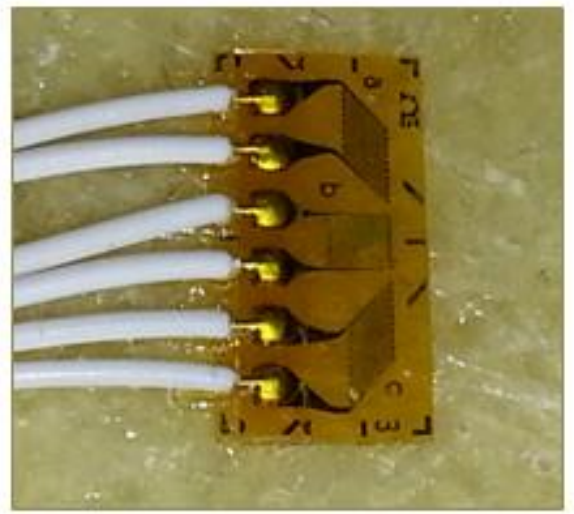

Figure 5: Rectangular rosette strain gauge
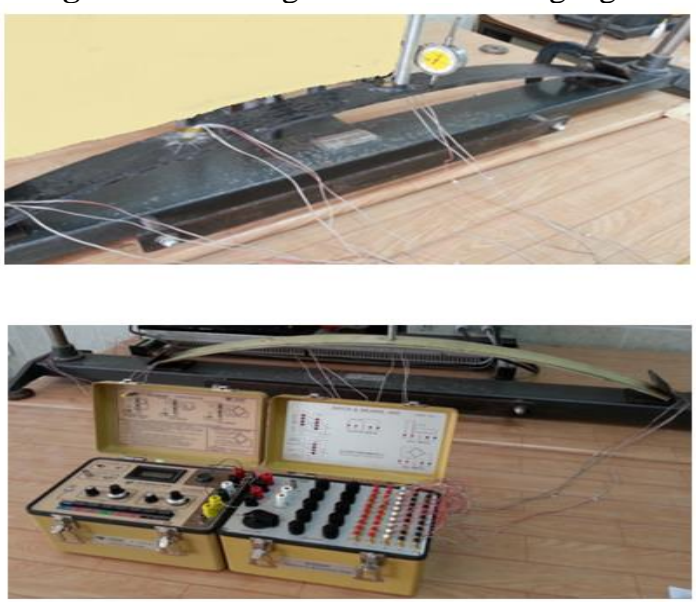

Figure 6: Application of rectangular rosette strain gauges in different modes of composite

Shells under bending test

\section{Results and Discussion}

The contour stress distributions through the laminated composite shell for Carbon, Glass, and Kevlar as reinforced fibers with epoxy as matrix material are represented in Figure 1. Maximum and minimum principal stresses were evaluated approximately using software ANSYS 14. The modulus of elasticity E and Poisson's ratio $\vartheta$ were obtained experimentally using tensile strength and strain gauge instruments. The values $(E, \vartheta)$ were taken as input data for ANSYS. It is noted that the carbon fiber has highest strength than the other types. The presence of carbon particles through the fibers material gives more strength to the material.

Experimental results from bending test under static loads were measured using rosette strain gauge technique. The strains $\left(\varepsilon_{\mathrm{a}}, \varepsilon_{\mathrm{b}}, \varepsilon_{\mathrm{c}}\right)$ were measured experimentally in three direction angles $\left(0^{0}, 45^{0}, 90^{\circ}\right)$ using rosette strain gauge. Then the maximum principal directions $\theta$, maximum principal stress $\sigma_{1}$, minimum principal stress $\sigma_{2}$, and maximum shear stress $\tau_{\mathrm{xy}}$ were calculated using Equations 1,2,3,4\&5 as shown in Figures 7, 8, and 9. The principal direction $\theta$ represents the plane or axis at which the maximum stress occurs. Angle $\theta$ may be in the first quadrant or other quadrant depends on the values of strains. Principal direction $\theta$ was determined exactly by using the Mohr's circle. The negative sign represents the loading is compression while the positive sign represents the loading is tension.

It is observed that the variation of stresses with their directions in 3D are given (ones represent longitudinal direction $\mathrm{x}$-axis and the other represent loads magnitude). The maximum principal stress occurs at $x=0.265 \mathrm{~m}$ from its supports at the first quarter of the shell laminate and the minimum principal stress occurs at the mid-span region of the shell laminate $(x=0.53 \mathrm{~m})$. It is noted that from figures, the carbon shell's strength is higher than glass shell's strength under the same load. This is due to carbon fibers have a good properties than other material. Any increase in carbon content in fiber particles causes an increase in strength properties. Also the woven properties give us higher strength than discontinuous glass fibers.

Table 1 shows the results obtained from tensile test of the three composite materials. It's found that the modulus of elasticity and tensile strength of Carbon-Epoxy are greater than Kevlar-Epoxy and Glass-Epoxy. This is attributed to many reasons such as (1) Woven fibers better than discontinuous fibers in carrying load (2) Carbon content in fibers affect to the strength of fibers and then laminate shell. 
Toughness is one of the most important characteristics for structural component materials. The Charpy test measures the impact energy or energy absorbed during the fracture, which refers to the material's toughness. Table 2 shows the toughness of three composite materials. It's noted that Kevlar-Epoxy has greater toughness (6.3 J) than Carbon-Epoxy and Glass-Epoxy, the Glass-Epoxy comes in the second degree $(4.2 \mathrm{~J})$ and the least value of toughness refers to the Carbon-Epoxy $(2.1 \mathrm{~J})$. This is due to the physical properties of Kevlar fibers which are used in the fabrication of dress resistant shots and other military purposes.

Table 3 shows the value of measured densities of three composite materials (Carbon-Epoxy, Glass-Epoxy and Kevlar-Epoxy). It's found that density of Glass -Epoxy is higher than Carbon-Epoxy and Kevlar-Epoxy, also it's noted that Kevlar-Epoxy has the least value of density.

Tables 4,5 and 6 show a comparison between the experimental principal stresses and Von Mises stresses with ANSYS results. It's can be noted that there are differences between the results obtained from both methods, and this may be attributed to many reasons such as (1) In numerical analysis poisson's ratios was taken from references and these values may be different from actual values of poisson's ratios in experimental work (2) There may be some errors in installation of strain gages on structures such as the strain gages position not exactly at desire angle or at desire locations (3) Woven Carbon fiber and Kevlar fiber were used in experimental while in FE analysis (ANSYS) was dealt with isotropic materials.
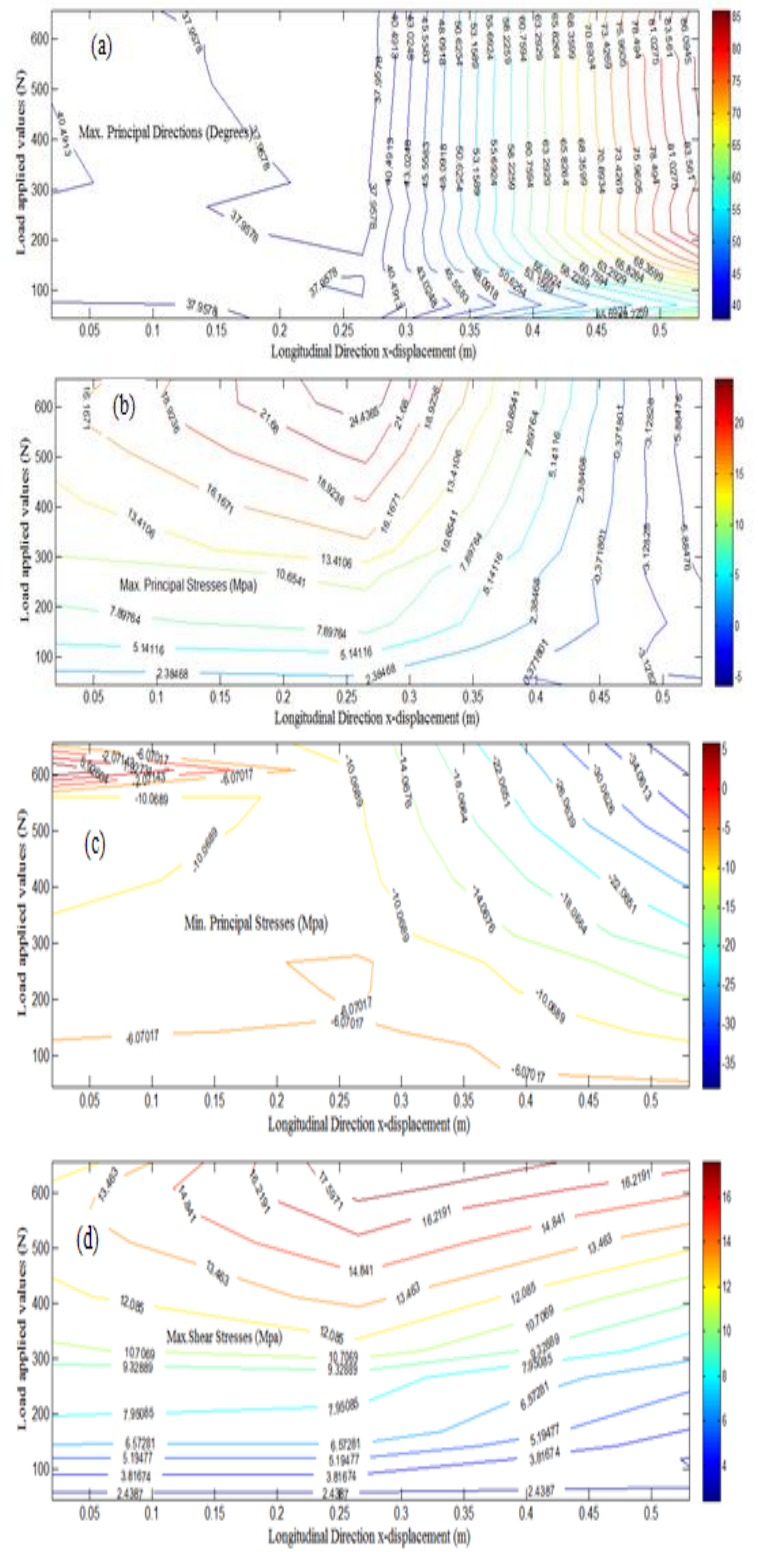

Figure 7: Experimental Results Contours from bending test of Carbon-Epoxy (a) Max. Principal directions $\theta$ (Degrees) (b) Max. Principal Stresses (Mpa) (c) Min. Principal Stresses (Mpa) (d) Max. Shear Stresses (Mpa)
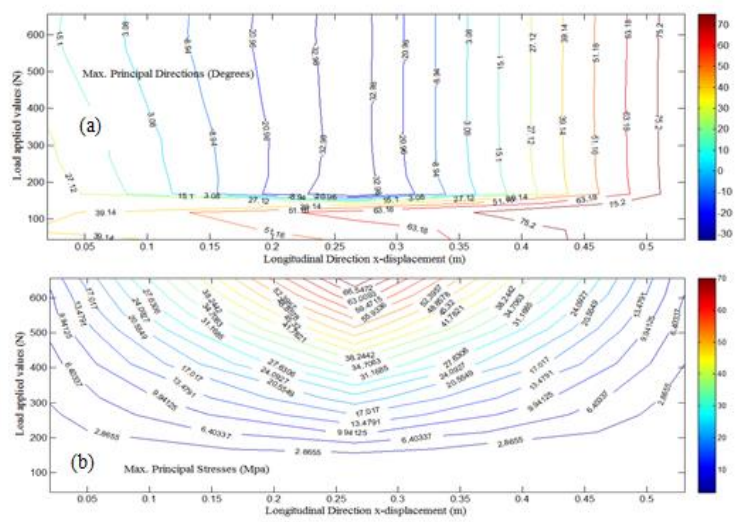

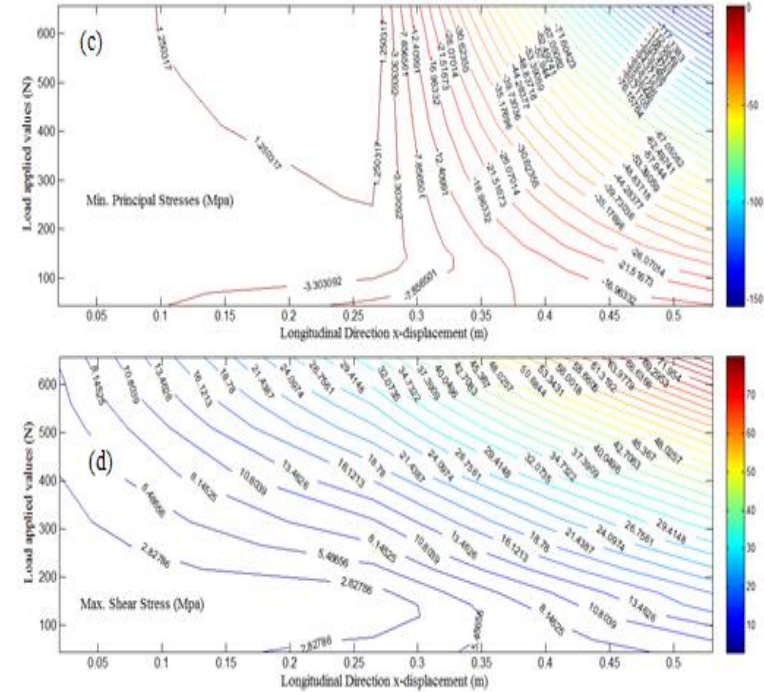

Figure 8: Experimental Results Contours from bending test of Glass-Epoxy

(a) Max. Principal directions $\theta$ (Degrees) (b) Max. Principal Stresses (Mpa)

(c) Min. Principal Stresses (Mpa) (d) Max. Shear Stresses (Mpa)
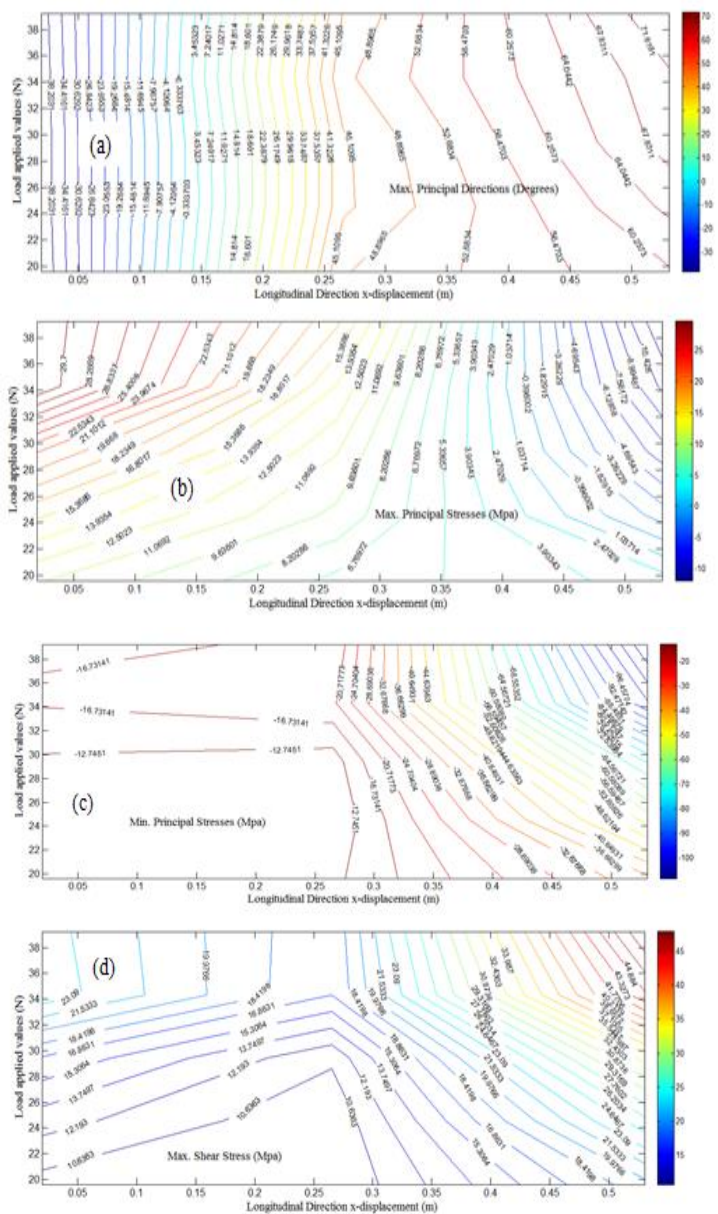

Figure 9: Experimental Results Contours from bending test of Kevlar-Epoxy

(a) Max. Principal directions $\theta$ (Degrees) (b) Max. Principal Stresses (Mpa)

(c) Min. Principal Stresses (Mpa) (d) Max. Shear Stresses (Mpa)
Table 3 Measured densities of the three composite materials.

\begin{tabular}{|r|c|}
\hline Material & Density $\left(\mathbf{k g} / \mathbf{m}^{\mathbf{3}}\right)$ \\
\hline Carbon-Epoxy & 1600 \\
\hline Glass-Epoxy & 2260 \\
\hline Kevlar-Epoxy & 1400 \\
\hline
\end{tabular}

Table 4 Comparison of experimental and ANSYS program stresses for Carbon-Epoxy composite shell.

\begin{tabular}{|c|c|c|c|c|c|c|}
\hline & \multicolumn{2}{|c|}{$\begin{array}{c}\text { Max. Principal Stress } \\
\text { (Mpa) }\end{array}$} & \multicolumn{2}{c|}{$\begin{array}{c}\text { Min. Principal } \\
\text { Stress(Mpa) }\end{array}$} & $\begin{array}{c}\text { Max.Von Mises Stress } \\
\text { (Mpa) }\end{array}$ \\
\hline Load (M) & Experimental & ANSYS & Experimental & ANSYS & Experimental & ANSYS \\
\hline 44.145 & 1.707036 & 3.6243 & -3.93923 & -5.3733 & 5.015568 & 7.841068 \\
\hline 68.67 & 2.748991 & 4.1676 & -9.67678 & -0.5277 & 11.3048 & 9.337269 \\
\hline 117.72 & 5.876647 & 5.2543 & -9.56629 & -8.8368 & 13.50062 & 12.33401 \\
\hline 142.24 & 7.541765 & 5.79 & -11.0266 & -9.9914 & 16.17476 & 13.82759 \\
\hline 166.77 & 8.988209 & 6.3411 & -11.9275 & -11.14 & 18.17303 & 15.32805 \\
\hline 215.82 & 10.18863 & 7.428 & -14.8048 & -13.455 & 21.76767 & 18.33456 \\
\hline 264.87 & 11.55637 & 8.5 & -17.4729 & -15.765 & 25.31351 & 21.32575 \\
\hline 313.92 & 15.32991 & 9.7905 & -21.1315 & -18.074 & 31.70943 & 24.48422 \\
\hline 412.02 & 18.96184 & 14.622 & -26.7873 & -22.693 & 39.81262 & 32.56673 \\
\hline 510.12 & 22.485338 & 19.815 & -33.2845 & -27.311 & 48.59901 & 40.98405 \\
\hline 559.17 & 23.89617 & 21.114 & -36.0169 & -29.621 & 52.23901 & 44.1432 \\
\hline 608.22 & 26.15484 & 22.412 & -38.5888 & -31.93 & 56.41324 & 47.30156 \\
\hline 65.27 & 27.19301 & 23.71 & -42.0588 & -34.24 & 60.43263 & 50.46159 \\
\hline
\end{tabular}

Table 5 Comparison of experimental and ANSYS program stresses for Glass-Epoxy composite shell.

\begin{tabular}{|c|c|c|c|c|c|c|}
\hline & \multicolumn{2}{|c|}{$\begin{array}{c}\text { Max. Principal Stress } \\
\text { (Ipa) }\end{array}$} & \multicolumn{2}{c|}{$\begin{array}{c}\text { Min. Principal Stress } \\
\text { (Mpa) }\end{array}$} & \multicolumn{2}{c|}{$\begin{array}{c}\text { Max.Von Mises Stress } \\
\text { (Mpa) }\end{array}$} \\
\hline Load (N) & Experimental & ANSYS & Experimental & ANSYS & Experimental & ANSYS \\
\hline 44.145 & 0.994076 & 1.1887 & -7.47788 & -0.9159 & 17.47234 & 2.847825 \\
\hline 68.67 & 1.031515 & 1.8491 & -16.9541 & -2.0609 & 21.21276 & 4.429918 \\
\hline 1117.72 & 1.551499 & 1.3464 & -20.6782 & -3.2058 & 29.98404 & 6.278032 \\
\hline 142.24 & 1.708134 & 1.6157 & -29.1782 & -5.4956 & 34.23418 & 7.578148 \\
\hline 166.77 & 3.976 & 4.0392 & -33.3481 & -6.64 & 40.52219 & 9.676593 \\
\hline 215.82 & 10.57111 & 10.771 & -38.3876 & -7.0026 & 53.29344 & 25.80446 \\
\hline 264.87 & 16.90107 & 16.157 & -47.2157 & -18.674 & 66.70224 & 38.70615 \\
\hline 313.92 & 22.67251 & 22.889 & -56.626 & -28.01 & 80.57833 & 54.83381 \\
\hline 412.02 & 36.73302 & 36.353 & -87.9725 & -39.681 & 110.9954 & 87.08912 \\
\hline 510.12 & 51.55913 & 51.163 & -111.865 & -63.023 & 144.7055 & 122.5704 \\
\hline 559.17 & 58.78167 & 56.548 & -126.214 & -98.036 & 163.7202 & 135.4713 \\
\hline 608.22 & 66.68166 & 67.319 & -141.117 & -116.71 & 183.7673 & 161.2758 \\
\hline 657.27 & 73.62294 & 72.705 & -158.119 & -126.05 & 205.0928 & 174.1812 \\
\hline
\end{tabular}

Table 6 Comparison of experimental and ANSYS program stresses fo Kevlar-Epoxy composite shell.

\begin{tabular}{|c|c|c|c|c|c|c|}
\hline & \multicolumn{2}{|c|}{$\begin{array}{l}\text { Max. Principal Stress } \\
\text { (Mpa) }\end{array}$} & \multicolumn{2}{|c|}{$\begin{array}{l}\text { Min. Principal Stress } \\
\text { (Mpa) }\end{array}$} & \multicolumn{2}{|c|}{$\begin{array}{l}\text { Max.Von Nises Stress } \\
\text { (.1pa) }\end{array}$} \\
\hline $\operatorname{Load}(\mathrm{N})$ & Experimental & ANSYS & Experimental & AISYS & Experimental & ANSYS \\
\hline 19.62 & 11.20575 & 12.469 & .35 .6609 & -22.044 & 42.38959 & 30.27013 \\
\hline 24.525 & .56906 & 13.58 & .53 .8576 & -23.98 & 63.09957 & 32.94094 \\
\hline 29.43 & 24896 & 18.395 & .72 .997 & -35.171 & 85.6224 & 47.14176 \\
\hline 34.335 & 31.04107 & 28.56 & -100.009 & .53 & 118.6162 & 71.68231 \\
\hline 39.24 & 31.13317 & 29.63 & -112.403 & .55 .687 & 130.7788 & 75.02656 \\
\hline
\end{tabular}

\section{Conclusions}

1. The maximum stresses present near fixed ends in Carbon-Epoxy and Kevlar-Epoxy shells while exist in the mid-span of the shell in Glass-Epoxy shell. 
2. A high variations in deflection, stresses and strains were recorded for Kevlar-Epoxy shell, due to its high flexibility.

3. The type of fiber has great effect on the mechanical properties, this is the reason that the chopped Glass fiber-Epoxy shell was more affected by the applied load than the woven Carbon fiber-Epoxy shell (the chopped fibers have weak properties compared to the woven fibers).

4. A discrepancy is found between the experimental and ANSYS results.

\section{References}

[1]. R. A. Arciniega and J. N. Reddy, Consistent third-order shell theory with application to composite circular cylinder, AIAA Journal, 43(9), (2005).

[2]. B.Kuriakose, L.Sathyabhama, K. V. Valsarajan, (2012), Static Behavior of Laminated Composite Shells, Journal of the Institution of Engineers (India): Series A,. 93 (4), (2012), 251-257.

[3]. J. Arashmehr, G. H. Rahimi, S. F. Rasouli, Numerical and Experimental Stress Analysis of Stiffened Cylindrical Composite Shell under Transverse end Load, International Journal of Mechanical, Aerospace, Industrial, Mechatronic and Manufacturing Engineering, 6, (7), (2012).

[4]. Tomasz Nowak, Jerzy Schmidt, NonLinear Mechanical Analysis of the Composite Overwrapped Cylinder for Hydraulic Applications, Advances in Manufacturing Science and Technology, 37 (4), (2013).

[5]. Jafar Arashmehr, Gholam H. Rahimi, Seyed F. Rasouli, An Experimental and Numerical Investigation of a Grid Composite Cylindrical Shell Subjected to
Transverse Loading, Journal of Mechanical Engineering, 59, (12), (2013), 755-762.

[6]. Arashmehr Jafar, Rahimi Gholam Hossein, Rasouli Fazel, Stress analysis of clamped-free grid composite cylindrical shell under various end loading, Central South University Press and SpringerVerlag Berlin Heidelberg, 21, (2014), 2667-2672.

[7]. Ahmet N.Eraslan, Tolga Akis, Stress analysis in strain hardening two-layer composite tubes subject to cyclic loading of internal pressure, Int. J. Adv. Appl. Math. and Mech., 3,(2), (2015), 65-76.

[8]. L. Gangadhar and T. Sunil Kumar, Finite Element Buckling Analysis of Composite Cylindrical Shell with Cutouts Subjected to Axial Compression, International Journal of Advanced Science and Technology, 89, (2016), 45-52.

[9]. ANSYS Release 14, Structural Analysis Guide, SAS IP, Inc. 2013.

[10]. ASTM D3039/D3039M, Standard test method for tensile properties of polymer matrix composite materials, American Society for Testing Materials, 2013.

[11]. ASTM D6110, Standard test method for determining the Charpy impact resistance of notched specimens of plastics, United States of America, 2006.

[12]. ASTM D 792, Standard Test Methods for density and Specific Gravity (Relative Density) of Plastics by Displacement, 2008.

[13]. Richard S. Figliola, Donald E. Beasley, Theory and Design for Mechanical Measurements, sixth edition, by Wiley \& Sons,Inc. 2015. 